\title{
The relationship between fatty acid profiles in milk identified by Fourier transform infrared spectroscopy and onset of luteal activity in Norwegian dairy cattle
}

\author{
A. D. Martin, ${ }^{* 1}$ N. K. Afseth,† A. Kohler,‡ Å Randby,§ M. Eknæs,§ A. Waldmann,\# G. Dørum,Il I. Måge,† \\ and O. Reksen* \\ *Department of Production Animal Clinical Sciences, Norwegian University of Life Sciences, PO Box 8146, NO-0033 Oslo, Norway \\ †Nofima-Food Research Institute, Osloveien 1, 1430 Ås, Norway \\ ‡Department of Mathematical Sciences and Technology, and \\ §Department of Animal and Aquacultural Sciences, Norwegian University of Life Sciences, PO Box 5003, 1432 Ås, Norway \\ \#Department of Reproductive Biology, Institute of Veterinary Medicine and Animal Sciences, Estonian University of Life Sciences, \\ 51014 Tartu, Estonia \\ IIDepartment of Chemistry, Biotechnology and Food Science, Norwegian University of Life Sciences, PO Box 5003,1432 Ås, Norway
}

\begin{abstract}
To investigate the feasibility of milk fatty acids as predictors of onset of luteal activity (OLA), 87 lactations taken from 73 healthy Norwegian Red cattle were surveyed over 2 winter housing seasons. The feasibility of using frozen milk samples for dry-film Fourier transform infrared (FTIR) determination of milk samples was also tested. Morning milk samples were collected thrice weekly (Monday, Wednesday, Friday) for the first $10 \mathrm{wk}$ in milk (WIM). These samples had bronopol (2-bromo-2-nitropropane-1,3-diol) added to them before being frozen at $-20^{\circ} \mathrm{C}$, thawed, and analyzed by ELISA to determine progesterone concentration and the concentrations of the milk fatty acids C4:0, C14:0, C16:0, C18:0, and cis-9 C18:1 as a proportion of total milk fatty acid content using dry-film FTIR, and averaged by WIM. Onset of luteal activity was defined as the first day that milk progesterone concentrations were $>3 \mathrm{ng} / \mathrm{mL}$ for 2 successive measurements; the study population was categorized as early $(\mathrm{n}=47)$ or late $(\mathrm{n}=40)$ OLA, using the median value of 21 DIM as the cutoff. Further milk samples were collected 6 times weekly, from morning and afternoon milkings, these were pooled by WIM, and one proportional sample was analyzed fresh for fat, protein, and lactose content by the dairy company Tine SA, using traditional FTIR spectrography in the wet phase of milk. Daily energybalance calculations were performed in 42 lactations and averaged by WIM. Animals experiencing late OLA had a more negative energy balance in WIM 1, 3, 4, and 5 , with the greatest differences been seen in WIM 3 and 4. A higher proportion of the fatty acids were medium
\end{abstract}

Received January 15, 2015

Accepted April 3, 2015.

${ }^{1}$ Corresponding author: adam.martin@nmbu.no chained, C14:0 and C16:0, in the early than in the late OLA group from WIM 1. In WIM 4, the proportion of total fatty acid content that was $\mathrm{C} 16: 0$ predicted late OLA, with $74 \%$ sensitivity and $80 \%$ specificity. The long-chain proportion of the fatty acids C18:0 and cis-9 C18:1 were lower in the early than in the late OLA group. Differences were greatest in WIM 4 and 5 . Differences in concentrations of cis-9 C18:1 were seen between the groups from WIM 1. No relationship was seen between OLA and milk concentrations of either protein or fat, or between OLA and the milk fat:protein ratio. The differences in milk fatty acid proportions between the 2 groups are most likely related to differences in energy balance. The study shows that frozen milk samples can be tested for fatty acids by FTIR spectroscopy and that FTIR spectroscopy of milk can be used to provide real-time information about cow reproductive function.

Key words: dairy cow, reproduction, fatty acid, infrared

\section{INTRODUCTION}

Precision dairy farming has increased in recent years, responding to expansion and efficiency demands (Rutten et al., 2013). Today routine sampling and analysis of milk components are performed using traditional Fourier transform infrared (FTIR) spectrography in the wet phase of milk by dairy companies for price calculations and management purposes. As precision dairy farming continues to move forward, measurements will likely be conducted online at every milking in many production systems. The FTIR technique can be used to detect the components of milk; for example, milk fat fraction, lactose, milk proteins, and so on (Soyeurt et al., 2006; Kaylegian et al., 2009; Rutten et al., 2013). However, an FTIR measurement of minor components in milk samples is limited by the low concentrations 
of the analytes. Consequently, an initial drying step before FTIR analysis; that is, performing FTIR analysis on dried milk films, has been used to decrease detection limits and provide more certain predictions of milk components such as FA (Afseth et al., 2010). Dry-film FTIR has the potential to be automated and included in high-throughput industrial environments, for instance in dairy company laboratories or as part of automated milking systems to provide farmers with real-time information about cow milk fat composition (Afseth et al., 2010). Previously, the use of liquid infrared spectroscopy of milk has been used to provide realtime in-line analysis of milk composition on farm, with promising results (Kawasaki et al., 2008). Conducting large-scale trials on the effectivity of FTIR under different farming conditions is difficult as long as the milk samples tested have to be fresh, because the transport to and capacity of the laboratory increase the cost and logistical demands of such studies considerably. Therefore, establishing whether samples can be frozen and the FA fraction conserved adequately is of importance in developing this technology.

Dairy cow reproductive performance has declined over the last half century and is considered a major bottleneck in the dairy industry (Lucy, 2001). Early detection of subfertile cows could improve both reproductive efficiency and resource management by allowing an individual cow to receive targeted nutritional supplementation or treatment or be managed for an extended lactation (Dobson et al., 2007). Dairy cow reproductive performance can be measured phenotypically (e.g., calving interval) or endocrinologically [e.g., time from calving until onset of ovarian activity (OLA) after calving; Royal et al., 2000]. The advantage of the latter measurements is that they are not confounded by on-farm management decisions such as voluntary waiting period and estrus-detection methods. Thus, OLA provides a clearer illustration of the potential reproductive performance.

Precision farming systems have long sought to develop a cow-side test to monitor, and predict, dairy cow reproductive performance. This has been partially achieved, and automated, in DeLaval's Herd Navigator system, which has the ability to measure progesterone (Herd Navigator, DeLaval, Tumba, Sweden). However, the system is expensive, and technical challenges exist in reducing the cost of a direct progesterone test. Furthermore, once progesterone is detected, OLA has already occurred, which limits opportunities to optimize individual cow treatment and management strategy.

Almost all dairy cows will experience negative energy balance (NEBAL) postpartum (Bauman and Currie, 1980). However, when NEBAL is severe and prolonged, subfertility is likely to occur (Butler, 2003). An associa- tion exists between NEBAL and reproductive performance (Reksen et al., 2001), and milk composition and NEBAL (Reksen et al., 2002). Early OLA is associated with an increased probability for early AI, shorter interval to pregnancy, and a higher risk of pregnancy (Darwash et al., 1997a; Galvão et al., 2010).

Generally, cows suffering from NEBAL have a higher milk fat percentage and a lower milk protein percentage than those in positive energy balance (Grieve et al., 1986; Duffield et al., 1997; de Vries and Veerkamp, 2000). Consequently, milk fat:protein ratios (MFPR) have been used to identify cows at risk of disease and subfertility in the postpartum period (Grieve et al., 1986; Geishauser et al., 1998; Heuer et al., 1999). However, a recent population study found that MFPR were unreliable predictors of fertility (Madouasse et al., 2010a). However, because different milk FA have different origins, they are likely to yield more information about the metabolic status of a cow than a generalized milk fat measure (Bauman and Griinari, 2001; Bauman et al., 2006). Therefore, they may be more useful in predicting, or diagnosing, subfertile cows. Promising results have been seen using FA profiles to predict subclinical ketosis (Van Haelst et al., 2008). If milk fat composition data can be used to identify cows that are at increased risk of subfertility, or other conditions related to metabolic stress, aberrant results will be able to elicit immediate metaphylactic actions to address the problem at the cow and herd level.

The aims of this study were (1) to test the feasibility of performing dry-film FTIR on frozen milk samples, and (2) to determine the relationship between OLA and energy balance, MFPR, and milk FA concentration using dry-film FTIR.

\section{MATERIALS AND METHODS}

\section{Cows, Diets, Housing, and Management}

Data for this study were collected from 87 lactations (24 first, 15 second, and 48 >second lactations) occurring in 73 Norwegian Red cows over 2 winter housing seasons between fall 2006 and spring 2008 at the Norwegian University of Life Sciences. The cows were housed in freestalls with rubber mats and concrete slatted floors. Cows were identified electronically using neck collars so that access to feed and recording of experimental data were automated. The cows were fed from automated concentrate feeders and silage bins with vertical feed gates. Grass silage was placed in the bin twice daily, and feed remains were removed thrice weekly. Feed intake was calculated as the difference between when the gate opened and closed recorded by weigh cells underneath each feed bin (Randby et al., 
2012). Concentrates were fed from out-of-parlor automatic feeders, and the weight of concentrates delivered to each cow was recorded on a daily basis. The cows were milked twice daily, with milking commencing at 0615 and $1500 \mathrm{~h}$. The cows were weighed each time they left the milking parlor.

\section{Milk Sampling}

Cows were milked twice daily, and yields were recorded at each milking. Morning milk samples collected on Monday, Wednesday, and Friday from each cow for the first $10 \mathrm{wk}$ in milk (WIM) were conserved with bronopol (2-bromo-2-nitropropane-1,3-diol), cooled at $4^{\circ} \mathrm{C}$, and further stored at $-20^{\circ} \mathrm{C}$ within $1 \mathrm{~h}$ of collection. These samples were analyzed for progesterone by enzyme immunoassay and for milk FA by dry-film FTIR. Milk samples from 3 morning and 3 evening milkings from each cow were pooled, based on proportional production, conserved with bronopol, and stored at $4^{\circ} \mathrm{C}$. These samples were analyzed for fat, protein, and lactose with an infrared spectrophotometer (MilkoScan 6000, Foss Electric, Hillerød, Denmark). Energy-corrected milk yield was calculated from chemical composition of milk (Sjaunja et al., 1991).

\section{Energy Balance}

Daily energy balance (EB) calculations were performed on the 42 lactations (26 early OLA and 16 late OLA) that occurred in the first year of the study. Feed sampling and analyses, sheep digestibility trials, and rumen in sacco studies are described by Randby et al. (2010). The contents of $\mathrm{ME}$ and $\mathrm{NE}_{\mathrm{L}}$ in the feed were calculated from feed chemical composition and digestibility values according to van Es (1978). Daily EB (MJ of $\mathrm{NE}_{\mathrm{L}}$ ) was calculated as feed energy intake minus energy requirement for maintenance $(0.335 \times$ BW0.75) and milk yield $(3.036 \times \mathrm{kg}$ of $\mathrm{ECM}+0.0050321 \times$ $\mathrm{ECM}^{2}$; and for first-lactation cows, also growth; Ekern, 1991). Daily EB estimates were averaged per week to provide the EB according to WIM (DIM 0-6 = WIM 1 , and so on).

\section{Calibration Development and Dry-Film FTIR Analysis}

Dry-film FTIR spectroscopy was used both to develop the calibration for major FA in frozen, stored milk samples, and for the subsequent prediction of FA content in all frozen and stored milk samples of the study. The FA calibration was developed based on 3 different data sets (subsequently denoted data sets A, $\mathrm{B}$, and C) comprising a total of 422 samples, exclusively used for FTIR calibration. These data partly originated from the 87 lactations used in the present study and partly originated from independent samples. Data set A consisted of 219 fresh milk samples obtained from a feeding experiment (Randby et al., 2012). The 219 samples in data set A represent a subset of samples from the 87 lactations in the present study. All samples were measured with FTIR before freezing, and FTIR calibration of FA based on these samples has been previously described (Afseth et al., 2010). Data set B consisted of 102 samples obtained from the same design as data set A. These samples, however, were stored at $-20^{\circ} \mathrm{C}$ before FTIR analysis. Data set B was thus used to expand the FA calibration to account for physical freezing effects, but the reference analysis was the same as used for data set A. Data set C consisted of 101 milk samples obtained from a study conducted within the EU project "True Food: Traditional United Europe Food" (FOOD-CT-2006-016264). The study, which only included Norwegian Red cows, was performed on commercial dairy farms located throughout Norway in collaboration with Tine SA (Ås, Norway) dairies. The samples were stored at $-20^{\circ} \mathrm{C}$ before FTIR analysis.

Milk samples from the calibration data sets $\mathrm{A}$ to $\mathrm{C}$ were subjected to reference analysis based on gas chromatography for the comparison with dry-film FTIR spectroscopy. For data sets A and B, the reference analysis has been previously described (Afseth et al., 2010). For data set C, all milk samples were lyophilized (ThermovacTM-20, Froilabo, Ozoir-la-Ferriere, France). The FA in lyophilized milk samples were methylated directly using a described protocol (Ferlay et al., 2010). The FAME were injected by auto-sampler into a Trace-GC 2000 series gas chromatograph equipped with a flame ionization detector (Thermo Finnigan, Les Ulis, France). The FAME were separated on a $100 \mathrm{~m} \times$ $0.25 \mathrm{~mm}$ i.d. fused silica capillary column (CP-Sil 88, Chrompack, Middelburg, the Netherlands). The injector temperature was maintained at $255^{\circ} \mathrm{C}$ and the detector temperature at $260^{\circ} \mathrm{C}$. The initial oven temperature was held at $70^{\circ} \mathrm{C}$ for $1 \mathrm{~min}$, increased to $100^{\circ} \mathrm{C}$ at $5^{\circ} \mathrm{C} / \mathrm{min}$ (held for $2 \mathrm{~min}$ ), and then increased to $175^{\circ} \mathrm{C}$ at $10^{\circ} \mathrm{C} /$ min (held for $42 \mathrm{~min}$ ), and increased $5^{\circ} \mathrm{C} / \mathrm{min}$ to a final temperature of $225^{\circ} \mathrm{C}$ (held for $15 \mathrm{~min}$ ). The carrier gas was hydrogen; pressure was maintained constant during analysis. Peaks were routinely identified by retentiontime comparisons with commercial authentic standards containing a mixture of FAME (NCP \#463, Nu Chek Prep, Elysian, MN; Supelco \#37, Supelco, Bellefonte, PA; and O5632, Sigma Chemical, St. Louis, MO).

The concentration of individual FA was expressed in percent of total FA present in the sample (on a FAME basis). Five FA, namely C4:0, C14:0, C16:0, C18:0, and cis-9 C18:1, were used for the calibration. The 5 FA were chosen because they are abundant in milk, 
but the choice was also based on calibration accuracies obtained. In addition, summed FA parameters were calculated directly from the gas chromatography results: summed SFA and summed MUFA. All milk samples were analyzed with dry-film FTIR the same way. All samples, except the samples of data set A, were thawed in a fridge overnight. The samples were shaken in a vortex mixer (Whirlimixer, Scientific Industries, Bohemia, NY) for $10 \mathrm{~s}$. The milk samples were diluted with water $(75 \%$ milk, $25 \%$ water $)$ and shaken in a vortex mixer (Whirlimixer, Scientific Industries) for 5 additional seconds. Samples $(2.5 \mu \mathrm{L})$ were then transferred to sample well plates (silicon, 96 wells) and dried in an exicator with silica gel at room temperature for approximately $1 \mathrm{~h}$. Dry-film FTIR was performed using a high-throughput screening eXTension (HTS-XT) unit coupled to a Tensor 27 spectrometer (both Bruker Optik GmbH, Ettlingen, Germany), equipped with a DLaTGS detector. Spectra were recorded in transmission mode in the spectral region from 4,000 to $500 \mathrm{~cm}^{-1}$ with a resolution of $6 \mathrm{~cm}^{-1}$ and an aperture of $5.0 \mathrm{~mm}$. Background spectra of the silicon substrate were collected before each sample measurement to account for variation in water vapor and $\mathrm{CO}_{2}$. All samples were measured in triplicates.

\section{Assay of Milk Progesterone}

Progesterone concentrations were determined from whole milk by enzyme immunoassay (Waldmann, 1993), using the second antibody coating technique (Waldmann et al., 1999). The intra-assay coefficients of variation for whole milk at progesterone concentrations of 1.5 and $19.7 \mathrm{ng} / \mathrm{mL}$ were 9.2 and $5.3 \%$, respectively. The limit of sensitivity, using a $20-\mu \mathrm{L}$ sample, was $<0.5$ $\mathrm{ng} / \mathrm{mL}$.

\section{OLA}

The day of OLA after calving was determined using milk progesterone data. This was defined as the first day that milk progesterone concentrations were $>3 \mathrm{ng} /$ $\mathrm{mL}$ for 2 successive measurements (Garmo et al., 2009). The median value was calculated for OLA and used to categorize lactations according to early (on or before median day of OLA) or late OLA (after the median day of OLA). In one lactation accurate determination of OLA was not possible because sampling stopped after 55 DIM. This lactation was omitted from the calculation of descriptive statistics but included in analyses where OLA was categorized. Consequently, accurate assessment of the time from calving until OLA was possible in 86 lactations (23 first, 15 second, and 48 $>$ second lactations) in 72 individual cows.

\section{Statistical Analyses}

Calibration of Frozen Milk Samples for DryFilm FTIR Determination of FA. The FTIR spectra obtained from the calibration and the prediction data sets were preprocessed identically during data analysis; FTIR spectra were subjected to a standard quality check according to absorbance and noise levels. All spectra were subjected to second derivative by the Savitzky-Golay algorithm (Savitzky, 1964) using a polynomial of degree 2 and a window size of 9 points in total, followed by normalization by extended multiplicative signal correction (Martens and Stark, 1991). The spectral regions of 600 to $1,800 \mathrm{~cm}^{-1}$ and 2,800 to $3,200 \mathrm{~cm}^{-1}$ were selected for subsequent data analysis. Preprocessed spectra of the calibration data sets were used to develop multivariate regression models based on partial least squares regression (PLSR; Wold and Wold, 1983). Chemical reference values of FA composition (all FA expressed as percentage by weight of total FA content) were used in the PLSR modeling. The optimal number of PLSR factors of the calibration models was determined using segmented cross-validation using 20 segments. Samples for all segments were chosen in such a way that samples having a biological link, i.e., coming from the same animal on the same DIM and represented in data sets $\mathrm{A}$ and $\mathrm{B}$, were clustered in the same segment. The prediction errors of the crossvalidated PLSR models, expressed as root mean square error of cross-validation, and the correlation coefficients $\left(\mathrm{R}^{2}\right)$ were used as the major figures of merit to evaluate the developed calibration equations. The Unscrambler X 10.3 (CAMO PROCESS AS, Oslo, Norway) and Matlab, V. 8.1 (The Mathworks Inc., Natick, MA) were used for all data analysis.

Associations Between Milk Yield and Components, EB, and $\boldsymbol{O L A}$. Data were collected from on-farm data-recording systems (feed intake weights, milk recording data, laboratory results) and merged into a single Excel file for validation before they were transferred to Stata 12 (Stata Corp., College Station, TX) for statistical analysis. Statistical significance was determined by a $P$-value $<0.05$. Statistical analyses were performed at lactation level. Initial descriptive and distributive analyses were performed in STATA. Subsequently, the lactations were categorized according to time to OLA with the description early OLA and late OLA. The Student's $t$-test was used to determine whether differences existed between EB and the milk characteristics (ECM yield, milk protein, milk fat, milk fat:protein, C4:0, C14:0, C16:0, C18:0, cis- 9 C18:1) of animals with early versus late OLA. Logistic regression with the categorized outcome was used to determine the sensitivity and specificity of each of the following 
milk parameters individually as a predictor for late OLA. The dichotomous statistical analyses involving OLA were based on all 87 lactations, with the exception of calculations involving EB, which were based on 42 lactations. In this paper the study unit is lactation; 14 cows have contributed 2 lactations to the 87 lactations available to study. The lack of independence between these lactations has not been corrected for in the statistical analysis.

\section{RESULTS}

\section{OLA}

The mean, standard deviation, and median OLA for the lactations were calculated to be 24.9, 13.4, and 21 $\mathrm{d}$, respectively. The range of OLA seen in this study was between 7 and 84 DIM. When the lactations were categorized, 47 lactations had early OLA and 40 late OLA.

\section{$E B$}

Cows that experienced late OLA had, on average, deeper and more prolonged NEBAL than animals that experienced early OLA (Table 1, Figure 1). The largest difference between the 2 groups was in the third week of lactation. In both groups the trend in EB was positive from the first WIM. However, on average animals with early OLA entered positive EB before those in the late OLA group. The change between positive and negative EB occurred in the third and sixth WIM for the early-OLA and late-OLA groups, respectively.

\section{FTIR Calibration Development}

The FTIR calibration was developed based on 3 different data sets, comprising a total of 422 samples. The data sets $\mathrm{B}$ and $\mathrm{C}$ were added to take into account physical variation related to freezing of milk. The calibration results from frozen samples compared with gas chromatography from fresh samples are provided in Table 2. The table shows that calibration models of unsaturated FA features are generally modeled better than SFA features. This is in accordance with previous results (Afseth et al., 2010). In addition, the correlation coefficients are generally lower and the estimation errors are higher than as previously shown for corresponding measurements of fresh milk samples (Afseth et al., 2010). However, the estimation errors as provided in the table shows that these models are undoubtedly feasible for screening of FA features as performed in the present study.

\section{Temporal Pattern of Milk Characteristics}

When the milk fat fractions as determined by dryfilm FTIR were analyzed, no relationship was seen between the proportion of milk FA that were short chained (C4:0) and the dichotomous variable OLA. A relationship was seen between proportion of the MCFA C14:0 and C16:0 and the dichotomous variable OLA. Animals with early OLA had higher concentrations of MCFA in the milk fat fraction than animals with late OLA. This relationship was seen in each of the first 7 WIM for both C14:0 and C16:0, and between the seventh and tenth WIM for C14:0 (Table 3). The difference between the concentrations of these 2 MCFA between the 2 groups of cows is greatest in the first month after calving. A statistically significant relationship was seen in the first 6 WIM, whereby the earlyOLA group had lower proportion of the long-chain FA (LCFA) cis-9 C18:1 (oleic acid) in the milk FA fraction than the late-OLA group. Statistically significant differences were only detected between the LCFA C18:0 and the dichotomous variable OLA in WIM 4, although the early group had numerically lower concentrations of the FA in the FA fraction throughout the study period

The variability in the diagnostic properties of a test system using milk FA to predict early or late OLA varied between the individual FA. Table 4 shows the sensitivity, specificity, positive predictive value, and negative predictive values for the $3 \mathrm{FA}$ shown to have a significant relationship with OLA (C14:0, C16:0 and cis-9 C18:1) in the second, third, and fourth WIM. The table shows that while the sensitivity varies between the different variables, between 35 and $74 \%$, the specificity ranges from 74 to $85 \%$. Of the $3 \mathrm{FA}$ tested, C16:0

Table 1. Mean daily energy balance $\left(\mathrm{MJ}\right.$ of $\mathrm{NE}_{\mathrm{L}}$ ) by weeks in milk grouped by early or late onset of luteal activity

\begin{tabular}{|c|c|c|c|c|c|c|c|c|c|c|}
\hline \multirow{2}{*}{$\begin{array}{l}\text { Onset of } \\
\text { luteal activity }\end{array}$} & \multicolumn{10}{|c|}{ Weeks in milk } \\
\hline & 1 & 2 & 3 & 4 & 5 & 6 & 7 & 8 & 9 & 10 \\
\hline Late & $-48.8^{*}$ & -17.2 & $-11.6^{* *}$ & $-3.9^{*}$ & $-1.3^{*}$ & 3.5 & 7.0 & 8.4 & 12.5 & 11.8 \\
\hline
\end{tabular}

*,**A $t$-test was performed comparing late and early groups. ${ }^{*} 0.01 \leq P<0.05,{ }^{* *} 0.001 \leq P<0.01$. 


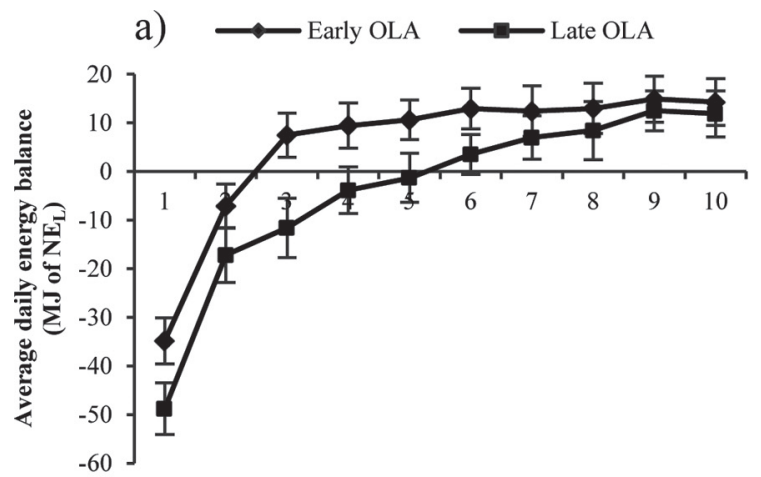

b)

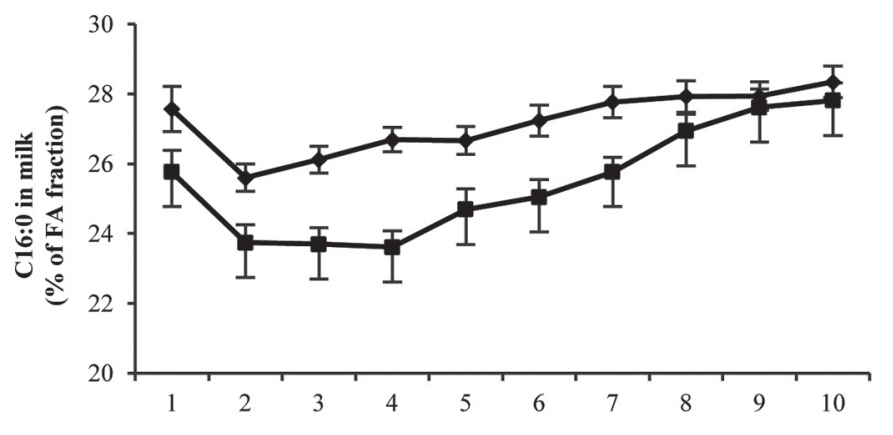

c)

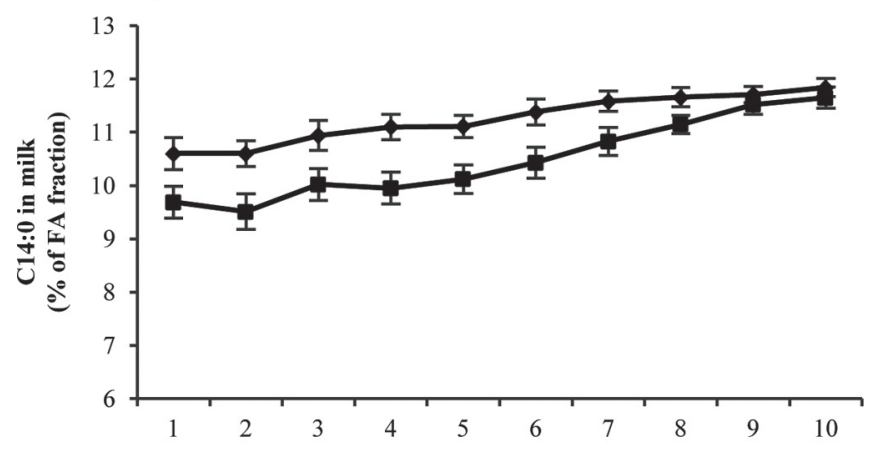

d)

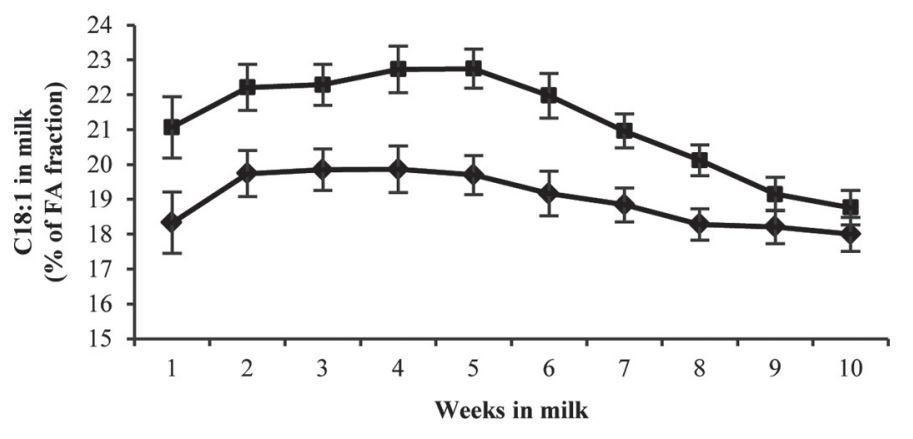

Figure 1. Graphs displaying mean values (error bars represent SEM) of (a) daily energy balance, (b) concentration of C16:0 in milk, (c) concentration of C14:0 in milk, and (d) concentration of cis-9 C18:1 in milk by weeks in milk grouped according to early or late onset of luteal activity (OLA). Parameters (b), (c), and (d) were estimated using dry-film Fourier transform infrared. in WIM 4 gave the most accurate predictions: sensitivity, specificity, positive predictive value, and negative predictive value of $74,80,76$, and $78 \%$, respectively.

Cows with late OLA produced more ECM than those with early OLA in the third and fourth weeks of lactation. Outside of these weeks no statistically significant relationship existed between ECM yield and OLA (Table 3). No statistically significant relationship was seen between milk protein, milk fat, or milk fat:protein ratio and the dichotomous variable OLA in the first $10 \mathrm{wk}$ of lactation with one exception. In WIM 8 cows with late OLA had statistically lower milk fat concentration that those with early OLA. A numerical trend existed for animals with early OLA to have higher concentrations of milk fat and milk protein than those with late OLA (Table 3).

\section{DISCUSSION}

This study shows that in a population of moderateyielding Norwegian Red cattle, it is possible to use dryfilm FTIR technology to accurately analyze the milk fat fraction after milk samples have been stored frozen. This is of great importance for upcoming studies on relationships among milk components, metabolic status, and reproduction in dairy cattle. The proportion of a single FA in the milk fat fraction, C16:0, in the fourth WIM measured in this way can be used to determine, with $74 \%$ sensitivity and $80 \%$ specificity, whether OLA occurred after 21 DIM. For this specific FA fraction, 4 times out of 5 , a cow identified as being at risk of having late OLA would go on to have it. Also, the predictive properties of other FA were high and motivate further investigations of relationships between metabolic function and single milk components. Such relationships in cows exposed to different feed rations and the exploration of amino acids in relation to OLA will be aims for further studies. Furthermore, the possibility of developing an extended model for the prediction of metabolic function and OLA after correction for milk yield, age, feed intake, and other relevant covariates will be explored in a planned experiment, as it probably offers a cheap and effective tool to help steer herd reproductive performance.

Fatty acids enter milk in 1 of 2 ways: they can be manufactured in the mammary gland de novo, or they can be absorbed from circulating blood (Bauman et al., 2006). The FA that are absorbed from blood can originate directly from the diet, be formed in the rumen by biohydration or degeneration, or can be released from body fat stores (MacGibbon, 2006). Previous work has shown that milk fat composition alters according to the metabolic state of the cow, which has been used to 
Table 2. Statistics and Fourier transform infrared (FTIR) calibration results for prediction of FA in frozen milk samples compared with gas chromatography ${ }^{1}$

\begin{tabular}{lccccccc}
\hline & \multicolumn{3}{c}{ Sample statistics $(\mathrm{n}=422)$} & & \multicolumn{2}{c}{ FTIR calibration results } \\
\cline { 2 - 3 } FA & Minimum & Maximum & Mean & SD & & $\mathrm{R}^{2}$ & RMSECV $^{2}$ \\
\hline C4:0 & 1.5 & 5.6 & 4.0 & 0.8 & & 0.82 & 0.3 \\
C14:0 & 6.0 & 15.1 & 12.1 & 1.1 & & 0.82 & 0.5 \\
C16:0 & 19.1 & 34.3 & 27.7 & 2.6 & & 0.81 & 1.1 \\
C18:0 & 6.0 & 15.2 & 10.8 & 1.5 & & 0.79 & 0.7 \\
cis-9 C18:1 & 12.2 & 35.4 & 18.5 & 2.9 & & 0.92 & 0.8 \\
SFA & 46.5 & 75.1 & 68.1 & 3.4 & & 0.88 & 1.2 \\
MUFA & 16.3 & 42.8 & 23.8 & 3.8 & & 0.93 & 1.0 \\
\hline
\end{tabular}

${ }^{1}$ All values, except $R^{2}$, expressed as percentage by weight of total FA content.

${ }^{2} \mathrm{RMSECV}=$ root mean square error of cross-validation.

identify cows with subclinical ketosis (Van Haelst et al., 2008).

In this study, consistent relationships were seen between higher concentrations of the MCFA measured and early OLA. The difference between the milk MCFA content between the early- and late-OLA groups peaked in the third and fourth WIM, the same time that the EB difference in the 2 groups was greatest. Broadly speaking, MCFA (those containing 10-16 carbon atoms) are synthesized almost exclusively de novo (Bauman et al., 2006). Consequently, animals with more NEBAL reduce de novo milk fat synthesis to conserve energy, thus having lower MCFA concentrations and late OLA.

Conversely, LCFA that contain more than 16 carbon atoms, are almost exclusively absorbed into milk from circulating blood (Bauman et al., 2006). Cows in NEBAL mobilize fat reserves, which increase blood and milk concentrations of LCFA (Stoop et al., 2009). This explains why the LCFA measured in this study, C18:0 (stearic acid) and cis-9 C18:1 (oleic acid), were consistently higher in the group of cows experiencing late OLA. The difference peaked in the fourth and fifth WIM and was apparent for oleic acid from the first WIM. Although clear numerical trends were seen throughout the early lactation period for both stearic and oleic acid, a statistically significant relationship was present for many more weeks for oleic acid. Ruminant adipose tissues are very rich in $\mathrm{C} 18: 0$ and $\mathrm{C} 18: 1$ FA, and the transition from pregnancy to lactation is accompanied by increases in the concentration of C18:0 FA and decreases in C18:1 FA in adipose tissue (Smith, 2009). Studies on plasma and hepatic lipid FA composition led to the hypothesis of a preferential release of oleic acid from the adipose tissue when ruminants experience a negative energy balance (Chilliard et al., 1977), which likely explains the relative importance of cis-9 C18:1 over C18:0 in this study.

Over the first 10 WIM the overall milk protein and fat content of animals in this study reduced, as is ex- pected and well described (Fox, 1998). However, the temporal pattern of specific milk FA concentrations varied. The concentration of milk LCFA included in this study fell over the 10 -wk period. These are derived either from nutritional intakes or from body fat breakdown and are almost exclusively absorbed from circulating blood (Bauman et al., 2006). Consequently, if the diet is relatively stable and EB is becoming more positive, mobilization of body fat reserves reduces, resulting in less LCFA in blood and milk. Milk concentrations of MCFA increased in the first 10 WIM of this study, as has been previously described in another study (Karijord et al., 1982). The MCFA are primarily synthesized de novo in the mammary gland, and their increasing concentration in milk is associated with an improved EB (Garnsworthy et al., 2006; van Knegsel et al., 2007). The positive correlation between MCFA and EB and negative correlation between LCFA and EB seen in this study was described in a recent review of the literature (Moate et al., 2007) and can partially explain why MFPR are unreliable predictors of fertility. As one fat fraction decreases in line with falling EB, the other fat fraction increases, meaning that overall milk fat concentrations do not necessarily alter. Furthermore, milk fat content is influenced by a wide array of factors including breed, genetic variation within breed, parity, lactation stage, season, disease, EB, rumen function, feeding management, and nutrition, which complicates a simplistic ratio. This study could not verify the reported negative linear relationship between milk protein and EB (Coulon and Remond, 1991).

In this study no relationship between MFPR and OLA was found. Previous studies have shown that OLA is closely related to the reproductive performance of individual cows at the lactation level and that it is a more accurate predictor of potential reproductive performance than traditional measure of fertility (Royal et al., 2000). This supports the findings of population-based studies that found MFPR to be poor 


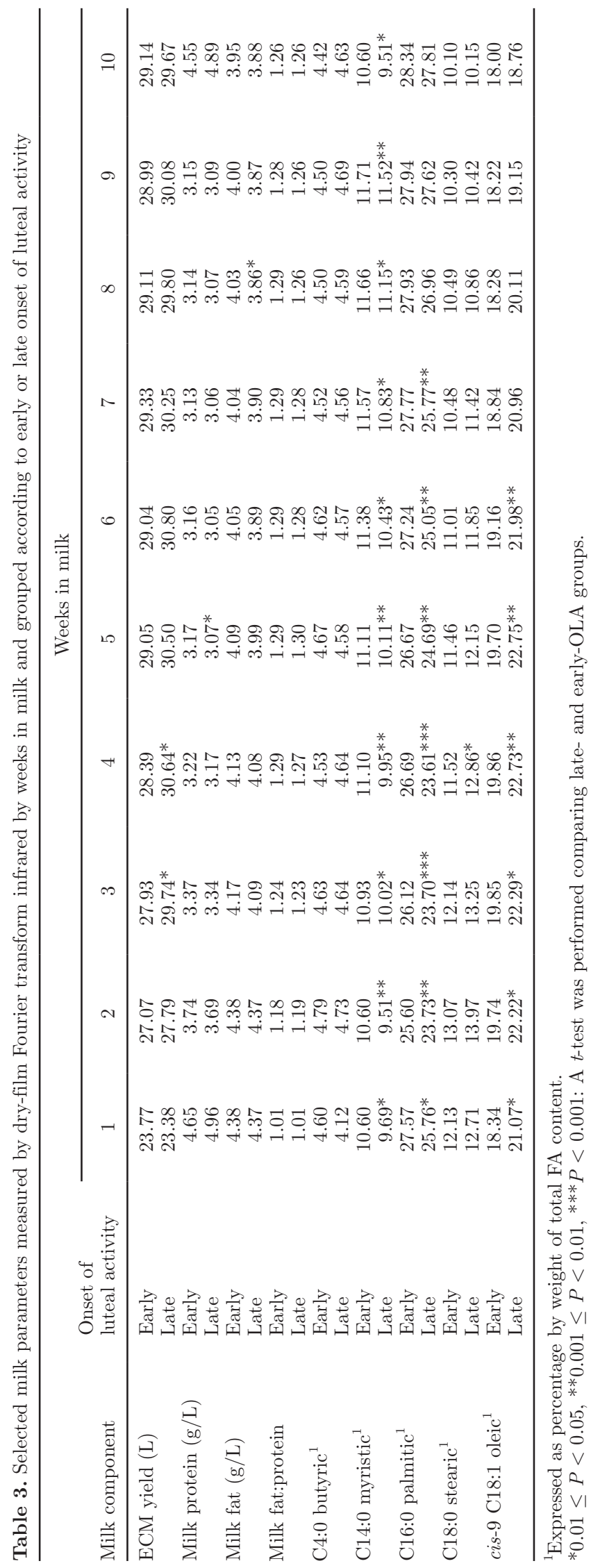

lactation-level predictors for reproductive performance (Madouasse et al., 2010a,b). However, it disagrees with several smaller studies that found MFPR to be linked with reproductive performance. One study noted that first-insemination pregnancy rates were 29 and $49 \%$ lower in animals with high-normal and abnormally high butterfat percentages, respectively, when compared with their normal counterparts (Kristula and Uhlinger, 1995). A further study found negative effects on fertility in animals with a first-test-day MFPR $>1.5$ (Heuer et al., 1999). Similarly, MFPR was found to be a useful predictor of whether cows were likely to exceed certain calving-to-conception intervals (Podpecan et al., 2008). Delayed return to cyclicity, reduced pregnancy rates, and decreased risk of pregnancy in animals with high MFPR ratios have also been shown (Loeffler et al., 1999; Gábor et al., 2008; Samarütel et al., 2008).

The animals in this study had a moderate ECM yield (averaging 2,008 $\mathrm{L}$ for the first $70 \mathrm{DIM}$ ). The effects of milk yield on OLA are difficult to determine in isolation, because high milk yields often result in larger NEBAL with subsequent delayed OLA (Petersson et al., 2006). This finding is supported by this study that showed that animals with early OLA had lower ECM yields in the third and fourth WIM than those with later OLA. Although, other studies have shown that milk yield per se has no effect on OLA (Darwash et al., 1997b; Lopez et al., 2005; Pedernera et al., 2008).

Norwegian Red cattle generally have earlier OLA than other dairy breeds (Royal et al., 2000; Petersson et al., 2006; Garmo et al., 2009). It is therefore surprising that such clear differences in OLA can be seen between FA profiles in this study. Furthermore, the distribution of OLA is more consistent in the Norwegian Red than in the Holstein breed, which has a higher proportion of cows experiencing both an early OLA and a very late OLA (Friggens et al., 2010). The bimodal distribution of OLA in Holstein cows may enhance the differences seen in milk FA profiles and OLA when compared with the study population, although this requires further research. In this study the outcome variable has been dichotomized, as either early or late OLA, because of the size and distribution of the study material. The functionality of the information would be improved if more than 2 outcomes were accounted for, and this requires further study.

Technically, this study was challenging to perform because the milk samples were frozen before analysis. Alterations in the physical stability of the milk, e.g., emulsion properties or protein denaturation, may occur upon thawing, affecting the physical properties of the milk. Thus, in this study, a calibration for prediction of FA features using FTIR was established, taking into account the possible physical changes in frozen stored 
Table 4. Sensitivity, specificity, and positive and negative predictive values for the ability of a univariate milk component measured by dry-film Fourier transform infrared to predict or detect late onset of luteal activity by weeks in milk (WIM)

\begin{tabular}{|c|c|c|c|c|c|c|c|c|c|}
\hline \multirow[b]{2}{*}{ Item } & \multicolumn{3}{|c|}{ C14:0 (WIM) } & \multicolumn{3}{|c|}{ C16:0 (WIM) } & \multicolumn{3}{|c|}{ cis-9 C18:1 (WIM) } \\
\hline & 2 & 3 & 4 & 2 & 3 & 4 & 2 & 3 & 4 \\
\hline Specificity (\%) & 84.78 & 74.47 & 75.00 & 78.26 & 74.47 & 79.55 & 82.22 & 76.60 & 79.55 \\
\hline Positive predictive value (\%) & 68.18 & 57.14 & 64.52 & 65.52 & 64.71 & 75.68 & 61.90 & 56.00 & 67.86 \\
\hline Negative predictive value $(\%)$ & 65.00 & 60.34 & 64.71 & 67.92 & 67.37 & 77.78 & 61.67 & 59.02 & 64.81 \\
\hline
\end{tabular}

samples. The standard liquid FTIR analysis, which is performed in narrow capillary cells of sizes in the 10- to $50-\mu \mathrm{m}$ range, can also easily be clogged by particles in the liquids, like frequently encountered in the analysis of frozen stored milk samples. The dry-film FTIR technique is not affected in the same way by particulate liquids, and in the present study, a calibration for FA composition taking into account physical changes in milk related to freeze storage was developed. Table 2 shows the calibration results are not as accurate as those obtained by fresh milk only (Afseth et al., 2010), but the estimation errors are still feasible for screening of FA features as performed in the present study. This opens the opportunity for rapid progression in this field because historically frozen samples can be analyzed and compared with complete data sets rather than waiting for new field trials to be performed. It also allows for samples to be gathered from farms in different areas to build a robust understanding of how milk FA composition may be used in precision farming.

The potential practical application of this work in the future is the incorporation of dry-film FTIR analysis into automated milking systems to provide the producer with real-time information about individual cows and herd performance. This study has focused on a link between milk metabolites and OLA, which is most likely explained by NEBAL. Precision-farming tools such as this are most likely to be applicable to high-input, intensive farming systems, and in this context individual dietary changes can be difficult to initiate, as cow DMI are often maximized. However, the knowledge that an individual cow is more likely to be subfertile would enable an active management decision to be made to place it in a group, or on a program, whereby lactation length was voluntarily, and deliberately extended, thus avoiding many of the costs associated with failed 365-d calving intervals (Dobson et al., 2007). Cow-level management has been recently shown to be economically beneficial to dairy farmers (Inchaisri et al., 2011). Changes in milk fat composition can also signal signs of metabolic stress before they are detectable by other means, e.g., blood BHBA measurements; this will allow early metaphylactic changes to be made to herd rations or management before clinical disease is seen (Van Haelst et al., 2008). Currently, many dairy herds already engage in regular, systematic sampling of blood and milk metabolites and use this information to make management changes at the herd level (Caraviello et al., 2006), and online FTIR FA-concentration analysis could replace this labor-intensive, relatively expensive exercise by allowing herd-management decisions to be made on the basis of real-time data.

\section{CONCLUSIONS}

This study shows that OLA is related to the proportion of some specific FA found in the milk fat fraction. These relationships can be seen as early as the first WIM. When OLA is dichotomized as early or late, univariate analysis indicated that prediction accuracy was highest in the fourth WIM. The study also shows that dry-film FTIR performed on previously frozen milk samples can determine milk FA composition.

\section{ACKNOWLEDGMENTS}

The authors acknowledge the work of Ellen Dahl for her assistance in analyzing the milk samples for progesterone content in the Hormone Laboratory in the Department of Production Animal Clinical Sciences (Oslo, Norway). Furthermore, we thank the staff at the research dairy farm at the Norwegian University of Life Sciences for their collaboration, sample collection, and animal care.

\section{REFERENCES}

Afseth, N. K., H. Martens, Å. Randby, L. Gidskehaug, B. Narum, K. Jørgensen, S. Lien, and A. Kohler. 2010. Predicting the fatty acid composition of milk: A comparison of two Fourier transform infrared sampling techniques. Appl. Spectrosc. 64:700-707.

Bauman, D. E., and W. B. Currie. 1980. Partitioning of nutrients during pregnancy and lactation - A review of mechanisms involving homeostasis and homeorhesis. J. Dairy Sci. 63:1514-1529.

Bauman, D. E., and J. M. Griinari. 2001. Regulation and nutritional manipulation of milk fat: Low-fat milk syndrome. Livest. Prod. Sci. 70:15-29. 
Bauman, D. E., I. H. Mather, R. J. Wall, and A. L. Lock. 2006. Major advances associated with the biosynthesis of milk. J. Dairy Sci. 89:1235-1243.

Butler, W. R. 2003. Energy balance relationships with follicular development, ovulation and fertility in postpartum dairy cows. Livest. Prod. Sci. 83:211-218

Caraviello, D. Z., K. A. Weigel, M. Craven, D. Gianola, N. B. Cook, K. V. Nordlund, P. M. Fricke, and M. C. Wiltbank. 2006. Analysis of reproductive performance of lactating cows on large dairy farms using machine learning algorithms. J. Dairy Sci. 89:4703-4722.

Chilliard, Y. S. D., J. Hervieu, M. Dorleans, and P. Morand-Fehr. 1977. Lipoprotein lipase activity and composition of omental adipose tissue as related to lipid metabolism of the goat in late pregnancy and early lactation. Ann. Biol. Anim. Biochim. Biophys. 17:1021-1033.

Coulon, J. B., and B. Remond. 1991. Variations in milk output and milk protein content in response to the level of energy supply to the dairy cow: A review. Livest. Prod. Sci. 29:31-47.

Darwash, A. O., G. E. Lamming, and J. A. Woolliams. 1997a. The phenotypic association between the interval to post-partum ovulation and traditional measures of fertility in dairy cattle. Anim. Sci. $65: 9-16$.

Darwash, A. O., G. E. Lamming, and J. A. Woolliams. 1997b. The phenotypic association between the interval to post-partum ovulation and traditional measures of fertility in dairy cattle. Anim. Sci. $65: 9-16$.

de Vries, M. J., and R. F. Veerkamp. 2000. Energy balance of dairy cattle in relation to milk production variables and fertility. J. Dairy Sci. 83:62-69.

Dobson, H., R. F. Smith, M. D. Royal, C. H. Knight, and I. M. Sheldon. 2007. The high-producing dairy cow and its reproductive performance. Reprod. Domest. Anim. 42:17-23.

Duffield, T. F., D. F. Kelton, K. E. Leslie, K. D. Lissemore, and J. H. Lumsden. 1997. Use of test day milk fat and milk protein to detect subclinical ketosis in dairy cattle in Ontario. Can. Vet. J. 38:713-718.

Ekern, A. 1991. A new system of energy evaluation of food for ruminants. Norsk Landbruksforskning 5:273-277.

Ferlay, A., B. Martin, S. Lerch, M. Gobert, P. Pradel, and Y. Chilliard. 2010. Effects of supplementation of maize silage diets with extruded linseed, vitamin $\mathrm{E}$ and plant extracts rich in polyphenols, and morning v. evening milking on milk fatty acid profiles in Holstein and Montbeliarde cows. Animal 4:627-640.

Fox, P. F., and P. L. H. McSweeney. 1998. Dairy Chemistry and Biochemistry. 1st ed. Blackie Acad. Prof., London, UK.

Friggens, N. C., C. Disenhaus, and H. V. Petit. 2010. Nutritional sub-fertility in the dairy cow: Towards improved reproductive management through a better biological understanding. Animal 4:1197-1213.

Gábor, G., F. Toth, L. Ozsvari, Z. Abonyi-Toth, and R. G. Sasser. 2008. Factors influencing pregnancy rate and late embryonic loss in dairy cattle. Reprod. Domest. Anim. 43:53-58.

Galvão, K. N., M. Frajblat, W. R. Butler, S. B. Brittin, C. L. Guard, and R. O. Gilbert. 2010. Effect of early postpartum ovulation on fertility in dairy cows. Reprod. Dom. Anim. Zuchthygiene $455 \mathrm{e} 207-\mathrm{e} 211$.

Garmo, R. T., A. D. Martin, E. Thuen, Ø. Havrevoll, H. Steinshamn, E. Prestløkken, Å. Randby, M. Eknæs, A. Waldmann, and O. Reksen. 2009. Characterization of progesterone profiles in fall-calving Norwegian Red cows. J. Dairy Sci. 92:4919-4928.

Garnsworthy, P. C., L. L. Masson, A. L. Lock, and T. T. Mottram. 2006. Variation of milk citrate with stage of lactation and de novo fatty acid synthesis in dairy cows. J. Dairy Sci. 89:1604-1612.

Geishauser, T. D., K. E. Leslie, T. F. B. Duffield, and V. L. Edge. 1998. An evaluation of protein/fat ratio in first DHI test milk for prediction of subsequent displaced abomasum in dairy cows. Can. J. Vet. Res. 62:144-147.

Grieve, D. G., S. Korver, Y. S. Rijpkema, and G. Hof. 1986. Relationship between milk composition and some nutritional parameters in early lactation. Livest. Prod. Sci. 14:239-254.
Heuer, C., Y. H. Schukken, and P. Dobbelaar. 1999. Postpartum body condition score and results from the first test day milk as predictors of disease, fertility, yield, and culling in commercial dairy herds. J. Dairy Sci. 82:295-304.

Inchaisri, C., R. Jorritsma, P. L. Vos, G. C. van der Weijden, and H. Hogeveen. 2011. Analysis of the economically optimal voluntary waiting period for first insemination. J. Dairy Sci. 94:3811-3823.

Karijord, O., N. Standal, and O. Syrstad. 1982. Sources of variation in composition of milk-fat. Z Tierz Zuchtungsbio 99:81-93.

Kawasaki, M., S. Kawamura, M. Tsukahara, S. Morita, M. Komiya, and M. Natsuga. 2008. Near-infrared spectroscopic sensing system for on-line milk quality assessment in a milking robot. Comput. Electron. Agric. 63:22-27.

Kaylegian, K. E., D. A. Dwyer, J. M. Lynch, D. E. Bauman, J. R. Fleming, and D. M. Barbano. 2009. Impact of fatty acid composition on the accuracy of mid-infrared fat analysis of farm milks. J. Dairy Sci. 92:2502-2513.

Kristula, M., and C. Uhlinger. 1995. Dairy herd-health monitoringHandwritten records to monitor disease events. Comp. Cont. Educ. Pract. 17:1520.

Loeffler, S. H., M. J. de Vries, and Y. H. Schukken. 1999. The effects of time of disease occurrence, milk yield, and body condition on fertility of dairy cows. J. Dairy Sci. 82:2589-2604.

Lopez, H., D. Z. Caraviello, L. D. Satter, P. M. Fricke, and M. C Wiltbank. 2005. Relationship between level of milk production and multiple ovulations in lactating dairy cows. J. Dairy Sci. 88:2783-2793.

Lucy, M. C. 2001. Reproductive loss in high-producing dairy cattle: where will it end? J. Dairy Sci. 84:1277-1293.

MacGibbon, A. K. H., and M. W. Taylor. 2006. Composition and structure of bovine milk lipids. Pages 1-42 in Advanced Dairy Chemistry. Vol. 2: Lipids. P. F. Fox and P. L. H. McSweeney, ed. Springer, New York, NY.

Madouasse, A., J. N. Huxley, W. J. Browne, A. J. Bradley, I. L. Dryden, and M. J. Green. 2010a. Use of individual cow milk recording data at the start of lactation to predict the calving to conception interval. J. Dairy Sci. 93:4677-4690.

Madouasse, A., J. N. Huxley, W. J. Browne, A. J. Bradley, and M. J. Green. 2010b. Can we use milk recording data to predict reproduction? An improvement on the fat to protein ratio. Cattle Pract. 18:83-88.

Martens, H., and E. Stark. 1991. Extended multiplicative signal correction and spectral interference subtraction-New preprocessing methods for near-infrared spectroscopy. J. Pharm. Biomed. 9:625-635.

Moate, P. J., W. Chalupa, R. C. Boston, and I. J. Lean. 2007. Milk fatty acids. I. Variation in the concentration of individual fatty acids in bovine milk. J. Dairy Sci. 90:4730-4739.

Pedernera, M., S. C. Garcia, A. Horagadoga, I. Barchia, and W. J. Fulkerson. 2008. Energy balance and reproduction on dairy cows fed to achieve low or high milk production on a pasture-based system. J. Dairy Sci. 91:3896-3907.

Petersson, K. J., H. Gustafsson, E. Strandberg, and B. Berglund. 2006. Atypical progesterone profiles and fertility in Swedish dairy cows. J. Dairy Sci. 89:2529-2538.

Podpecan, O., J. Mrkun, and P. Zrimsek. 2008. Diagnostic evaluation of fat to protein ratio in prolonged calving to conception interval using receiver operating characteristic analyses. Reprod. Domest. Anim. 43:249-254.

Randby, Å. T., P. Nørgaard, and M. R. Weisbjerg. 2010. Effect of increasing plant maturity in timothy-dominated grass silage on the performance of growing/finishing Norwegian Red bulls. Grass Forage Sci. 65:273-286.

Randby, Å. T., M. R. Weisbjerg, P. Nørgaard, and B. Heringstad. 2012. Early lactation feed intake and milk yield responses of dairy cows offered grass silages harvested at early maturity stages. J. Dairy Sci. 95:304-317.

Reksen, O., Y. T. Gröhn, Ø. S. Havrevoll, T. Bolstad, A. Waldmann, and E. Ropstad. 2001. Influence of concentrate allocation and en- 
ergy balance on postpartum ovarian activity in Norwegian cattle. J. Dairy Sci. 84:1060-1068.

Reksen, O., Ø. Havrevoll, Y. T. Gröhn, T. Bolstad, A. Waldmann, and E. Ropstad. 2002. Relationships among body condition score, milk constituents, and postpartum luteal function in Norwegian dairy cows. J. Dairy Sci. 85:1406-1415.

Royal, M. D., A. O. Darwash, A. P. E. Flint, R. Webb, J. A. Woolliams, and G. E. Lamming. 2000. Declining fertility in dairy cattle: Changes in traditional and endocrine parameters of fertility. Anim. Sci. 70:487-501.

Rutten, C. J., A. G. J. Velthuis, W. Steeneveld, and H. Hogeveen. 2013. Invited review: Sensors to support health management on dairy farms. J. Dairy Sci. 96:1928-1952.

Samarütel, J., A. Waldmann, K. Ling, H. Jaakson, T. Kaart, A. Leesmae, and O. Kart. 2008. Relationships between luteal activity, fertility, blood metabolites and body condition score in multiparous Estonian Holstein dairy cows under different management. J. Dairy Res. 75:485-490.

Savitzky, A., and M. J. E. Golay. 1964. Smoothing and differentiation of data by least squares procedures. Anal. Chem. 36:1627-1639.

Sjaunja, L. O., L. Baevre, L. Junkkarinen, J. Pedersen, and J. Setala. 1991. Measurement of the total energy content of cows milk and the energy value of milk-fat and milk protein. Eaap Public 50:152-155.

Smith, S. B., C. A. Gill, D. K. Lunt, and M. A. Brooks. 2009. Regulation of fat and fatty acids composition in beef cattle. Asianaustralas. J. Anim. Sci. 22:1225-1233.
Soyeurt, H., P. Dardenne, F. Dehareng, G. Lognay, D. Veselko, M. Marlier, C. Bertozzi, P. Mayeres, and N. Gengler. 2006. Estimating fatty acid content in cow milk using mid-infrared spectrometry. J. Dairy Sci. 89:3690-3695

Stoop, W. M., H. Bovenhuis, J. M. L. Heck, and J. A. M. van Arendonk. 2009. Effect of lactation stage and energy status on milk fat composition of Holstein-Friesian cows. J. Dairy Sci. 92:1469-1478.

van Es, A. J. H. 1978. Feed evaluation for ruminants. I. The systems in use from May 1977 onwards in the Netherlands. Livest. Prod. Sci. 5:331-345.

Van Haelst, Y. N., A. Beeckman, A. T. Van Knegsel, and V. Fievez, 2008. Short communication: Elevated concentrations of oleic acid and long-chain fatty acids in milk fat of multiparous subclinical ketotic cows. J. Dairy Sci. 91:4683-4686.

van Knegsel, A. T., H. van den Brand, J. Dijkstra, W. M. van Straalen, M. J. Heetkamp, S. Tamminga, and B. Kemp. 2007. Dietary energy source in dairy cows in early lactation: Energy partitioning and milk composition. J. Dairy Sci. 90:1467-1476.

Waldmann, A. 1993. Enzyme immunoassay (EIA) for milk progesterone using a monoclonal antibody. Anim. Reprod. Sci. 34:19-30.

Waldmann, A., E. Ropstad, K. Landsverk, K. Sørensen, L. Sølverød, and E. Dahl. 1999. Level and distribution of progesterone in bovine milk in relation to storage in the mammary gland. Anim. Reprod. Sci. 56:79-91.

Wold, S. M. H., and H. Wold. 1983. The multivariate calibration problem in chemistry solved by the PLS method. Lect. Notes Math. 973:286-293. 